Session 1566

\title{
A Demonstration Unit to Enhance Heat Transfer Lectures on Natural and Forced Convection
}

\author{
Charles H. Forsberg \\ Department of Engineering, Hofstra University, Hempstead, NY 11549
}

\section{Overview}

As a professor for several courses in the thermal/fluids area of mechanical engineering I am always looking for ways to make lecture classes more interesting and beneficial for the students and for ways to increase and encourage student participation. Such increased student activity enhances the learning process and leads to improved student comprehension and retention of the course material.

This paper describes a demonstration unit which has been designed and constructed to accompany heat transfer lectures on natural and forced convection. The unit consists of two thin metal plates mounted in a wood frame. A flat electric resistance heater is sandwiched between the plates. Supports are provided so that the assembly can be positioned either horizontally or vertically. Instrumentation is provided to measure the temperatures of the plate surfaces and the surrounding air and also the power input to the heater. The unit is capable of experimental determination of natural convective coefficients for flat plates for vertical and horizontal orientations and for a variety of plate temperatures. For demonstrations involving forced convection, the unit includes a blower to provide a uniform flow of air across the surface of the plate. With measurements of air velocity, power input, and temperature, the convective coefficients for forced convection can be experimentally determined for a variety of plate temperatures.

The demonstration unit is small and portable, and is easy to set-up on the table in the front of the classroom. It is low-cost, utilizing instrumentation available in the engineering laboratories. In its typical use during a lecture class, the instructor first introduces the theoretical and empirical equations available for calculation of convective coefficients. Using these textbook equations, the students make calculations of convective coefficients for the parameters of the demonstration unit. The students then operate the demonstration unit and the actual convective coefficients for the flat plates are determined. A comparison is made between these experimentally-determined coefficients and the values predicted by the students. 
The paper describes the equipment in detail, including a parts list. It also suggests several demonstrations for the lecture class.

The demonstration unit has been well-received by the students, and it is now a permanent experiment in the senior level heat transfer laboratory.

\section{The Demonstration Unit}

The demonstration unit is shown in Figure 1. It consists of two thin (1/16" thick) aluminum plates mounted in a $3 / 4$ " plywood frame. The size of the plates is 12 " by 16.5 ". The outer surfaces of the plates are polished to give a low value of emissivity and minimize the heat transfer by radiation.

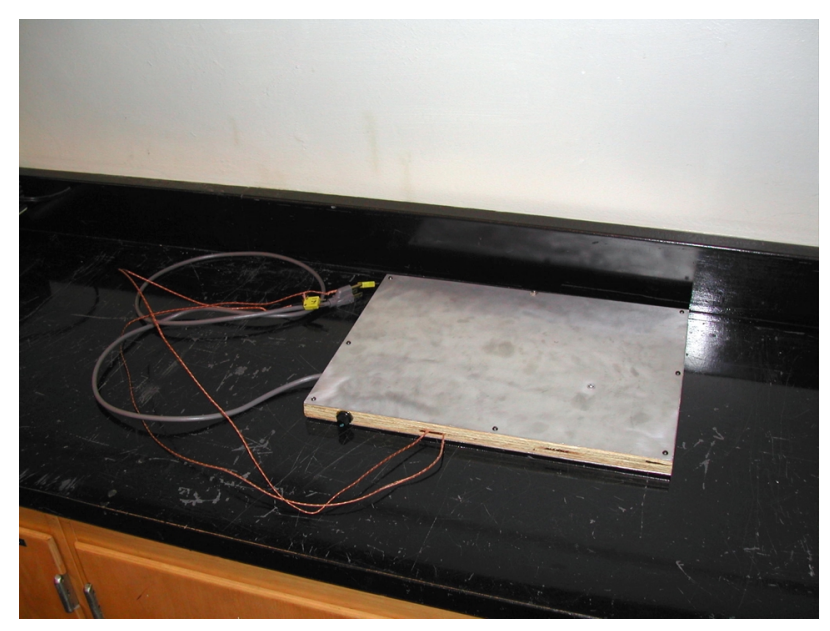

\section{Figure 1 - The Demonstration Unit}

A flexible heating tape (300 watts maximum) is sandwiched between the aluminum plates. A Type $\mathrm{K}$ thermocouple is attached to each plate to measure the plate temperature, and a cartridge fuse is provided to protect personnel. The plates are electrically grounded. In Figure 1, the thermocouple wires are shown leaving the wood frame in the front of the unit. The fuse holder is mounted in the wood frame and is seen near the front left corner of the unit. The line cord exits the demonstration unit on the left side of the unit. 
Figure 2 shows the internal layout of the unit - the heating tape, wiring, and cartridge fuse.

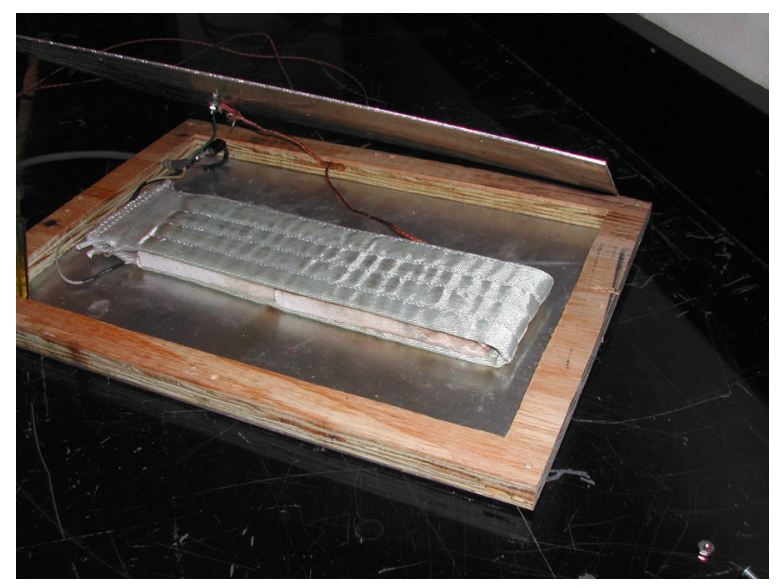

\section{Figure 2 - Internal Layout of the Unit}

\section{Equipment and Instrumentation}

The equipment and instrumentation have been selected so that it is portable and capable of easy set-up in a classroom. All of the equipment and instrumentation items were available from the Hofstra engineering laboratories. No expenditures for equipment or instrumentation for this project were needed.

The components are shown in Figures 3 and 4, as follows:

Figure 3 on the next page shows the two digital thermometers immediately to the left of the demonstration unit. Continuing going left, there is the variac autotransformer to adjust the power input to the heater. To the left of the variac is the small blower to provide an air stream for forced convection demonstrations. The blower is a small room heater which provides 3 levels of heat input to the air stream. We typically use the blower on its "fan-only" setting with no heating of the air flowing over the plate. However, the blower could also be used to investigate the effect of air stream temperature on forced convection from the plate.

"Proceedings of the 2003 American Society for Engineering Education Annual Conference \& Exposition Copyright (C) 2003, American Society for Engineering Education” 


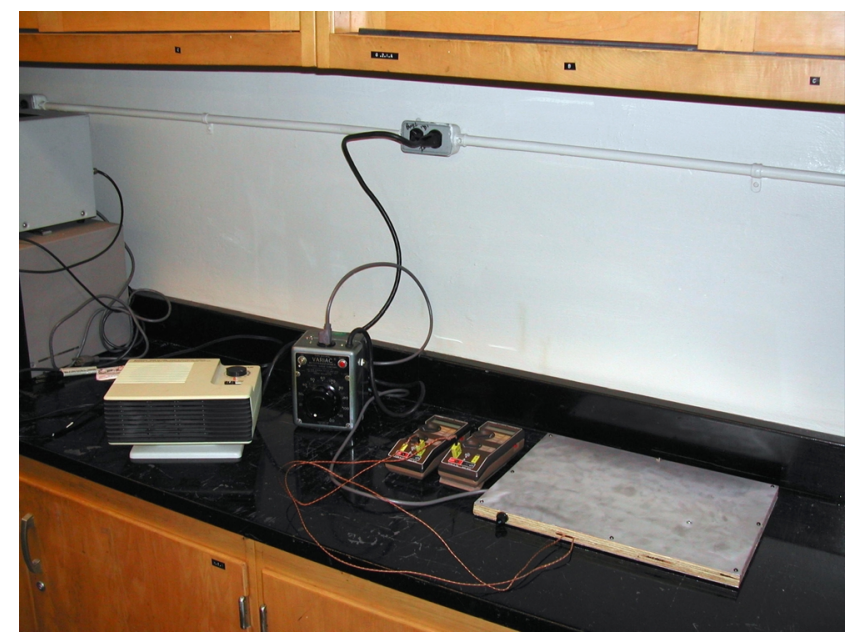

\section{Figure 3 - Equipment Items}

Figure 4 shows the power and air-velocity instrumentation. On the left is the power analyzer/data logger which measures the power input to the heater. On the right of the figure is the air-velocity meter to measure the air flow rate over the plate for forced convection runs. Between these two units is a small, very inexpensive power meter from Radio Shack. For voltages near the normal line voltage of $115 \mathrm{~V}$, the Radio Shack meter proved to be an excellent, accurate substitute for the higher cost power analyzer shown on the left of the figure. (Being designed for voltages near $115 \mathrm{~V}$, the Radio Shack meter was inappropriate for use at significantly lower voltages.)

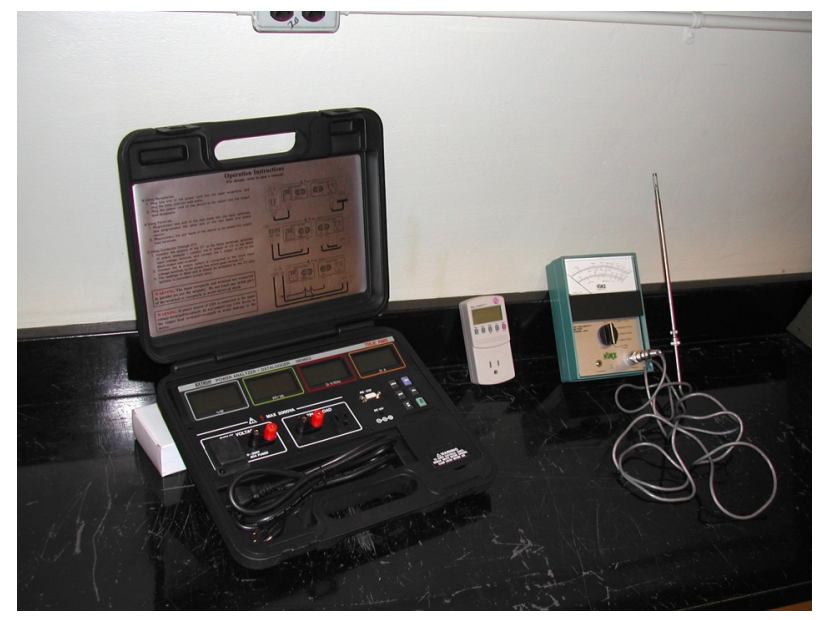

"Proceedings of the 2003 American Society for Engineering Education Annual Conference \& Exposition Copyright (C) 2003, American Society for Engineering Education” 


\section{Figure 4 - Power and Air-Velocity Instrumentation}

Other minor items (not shown) include a wood frame for hanging the demonstration unit vertically, supports for positioning the unit horizontally above the table top, and an insulating cover of fiberglas batts which can be attached on one side of the demonstration unit assembly. This insulating cover will cause most of the generated heat to pass through one of the two plates of the unit. This cover is used in some demonstrations with the plate in the horizontal position. The purpose of these horizontally-positioned demonstrations is to show that, even though the top and bottom plates are at the same temperature, the rate of heat transfer from the top surface of the plate is different from the heat transfer from the bottom surface. This observation is consistent with empirical predictions.

As mentioned above, all of the equipment and instrumentation items were readily available from the Hofstra engineering laboratories. A list of the items follows, with the estimated cost of these or similar items:

Two (2) Omega Engineering Model 871A Digital Thermometers

$\$ 250$ each

(Actually only one thermometer is needed since the meter has two channels) Includes Type K thermocouple.

Extech Power Analyzer/Data Logger Model 380803

$\$ 700$

Kill-A-Watt Power Meter Model P4400; P3 International

$\$ 30$ Radio Shack Cat. No. 63-1152

Variac Autotransformer; General Radio Co. Type W5LMT3 \$200 Load 0-120 V; $7.1 \mathrm{~A}$

Kurz Air Velocity Meter Model 441, with Thermal Anemometer Probe

Room Air Fan/Heater

$\$ 20$

Miscellaneous Items: Metal plates, wood frame and supports, $\$ 25$ cartridge fuse holder and fuse, line cord, insulating cover

The demonstration unit can be built by lab personnel in one or two days.

"Proceedings of the 2003 American Society for Engineering Education Annual Conference \& Exposition Copyright (C) 2003, American Society for Engineering Education” 


\section{Use of the Demonstration Unit in Lecture Class}

All of the equipment items are very portable and easy to transport to the classroom, either on a cart or separately by hand. The items are set-up on the desk in the front of the room.

The demonstration unit is used during heat transfer lectures which introduce students to natural and forced convection from flat plates. The instructor first describes the heat transfer phenomena and the governing theoretical and empirical equations for determining the convective heat transfer coefficients. The instructor then gives the students the typical input values for the demonstration unit operation (e. g., air velocity and temperature, plate temperature, plate size and orientation). Using the textbook equations, the students calculate the heat transfer coefficients and heat flows for the input parameters.

The students then operate the demonstration unit and the actual heat flows are measured. Since the measured heat flows include both radiative and convective heat flows, the measured heat flow values are adjusted to remove the radiative component. (Plate temperatures are kept below $250 \mathrm{~F}$. At these low temperatures, and with the low emissivity of the plates, the radiative component is small compared with the convective component.) The radiative component (and also the conductive component when the insulating cover is used) can be accurately estimated. These non-convective components are subtracted from the total measured heat flow to give the experimentally-determined convective heat flow. A comparison is made between this experimental value and the value predicted by textbook equations.

The following are suggested demonstration unit runs which can be performed during the class period. All of the runs are steady-state runs; that is, the heater is turned-on and temperature and power measurements are taken when the plate temperatures have stabilized.

1) With the unit horizontal, heat the plates to a given temperature and measure the power input to the heater. This will allow determination of the natural convective heat flow from the plates.

2) With the unit horizontal and the insulating cover placed on the upper plate, heat the exposed plate to a given temperature and measure the power input to the heater. This will allow determination of the natural convection heat transfer coefficient for a horizontal heated plate facing downwards.

3) With the unit horizontal and the insulating cover placed on the lower plate, heat the exposed plate to a given temperature and measure the power input to the heater. This will allow determination of the natural convection heat transfer coefficient for a

"Proceedings of the 2003 American Society for Engineering Education Annual Conference \& Exposition Copyright (C) 2003, American Society for Engineering Education” 
horizontal heated plate facing upwards.

4) With the unit vertical, heat the plates to a given temperature and measure the power input to the heater. This will allow determination of the natural convection heat transfer coefficient for a vertical plate.

5) Position the unit horizontally and place the insulating cover on the lower plate. Then position the blower and send a uniform stream of air over the exposed plate surface. Measure the velocity of the air flow, heat the exposed plate to a given temperature, and measure the power input to the heater. This will allow determination of the forced convection heat transfer coefficient for air flow over a heated flat plate.

\section{Sample Results}

Many experimental runs have been performed with the demonstration unit. Sample results are presented below for three natural convection runs: the unit positioned vertically, the unit positioned horizontally with the exposed heated plate facing upwards, and the unit positioned horizontally with the exposed heated plate facing downwards. First, brief descriptions of the pertinent equations are presented:

As discussed in all undergraduate heat transfer texts, the rate of heat transfer by convection from a surface is given by the equation:

$$
\mathrm{Q}_{\mathrm{conv}}=\mathrm{h} \cdot \mathrm{A} \cdot\left(\mathrm{T}_{\text {surf }}-\mathrm{T}_{\infty}\right)
$$

In this equation, "Q $\mathrm{Q}_{\text {conv }}$ " is the rate of heat transfer by convection, " $\mathrm{h}$ " is the convective coefficient, " $\mathrm{A}$ " is the surface area of the plate, " $\mathrm{T}_{\text {surf }}$ " is the surface temperature of the plate, and " $\mathrm{T}_{\infty}$ " is the air temperature.

The convective coefficient is obtained from the Nusselt number "Nu", and there is an empirical relation giving the relationship among the three dimensionless groups - the Nusselt number "Nu", the Prandtl number "Pr" and the Grashof number "Gr".

$$
\mathrm{Nu}=(\mathrm{h} \cdot \mathrm{L} / \mathrm{k})
$$

In this equation, " $\mathrm{L}$ " is the characteristic length of the problem. For a vertical plate, the characteristic length is the height of the plate. For a horizontal plate, the characteristic length is the surface area of the plate divided by the perimeter of the plate. " $\mathrm{k}$ " is the thermal 
conductivity of the surrounding air.

For natural convection, the relationship between the three dimensionless groups for vertical and horizontal plates is of the form:

$$
\mathrm{Nu}=\mathrm{C} \cdot(\mathrm{Gr} \cdot \mathrm{Pr})^{\mathrm{m}}
$$

In this equation, the parameters " $\mathrm{C}$ " and " $\mathrm{m}$ " have values dependent upon the geometry of the problem and the value of $(\mathrm{Gr} \cdot \mathrm{Pr})$. For the vertical plate with the $(\mathrm{Gr} \cdot \mathrm{Pr})$ values encountered with the demonstration unit, " $\mathrm{C}$ " is 0.59 and " $\mathrm{m}$ " is $1 / 4$. For the horizontal plate with the heated uninsulated surface facing upwards, " $\mathrm{C}$ " is 0.54 and " $\mathrm{m}$ " is $1 / 4$. For the horizontal plate with the heated uninsulated surface facing downwards, "C" is 0.27 and "m" is $1 / 4$.

Reference is not made to a specific text since these empirical relations are presented in virtually all undergraduate heat transfer texts.

As mentioned above, heat is transferred from a heated surface not only by convection, but also by radiation. The equation for heat transfer by radiation is:

$$
\mathrm{Q}_{\mathrm{rad}}=\epsilon \cdot \sigma \cdot \mathrm{A} \cdot\left(\mathrm{T}_{\text {surf }}^{4}-\mathrm{T}_{\text {surr }}^{4}\right)
$$

In this equation, " $\mathrm{Q}_{\mathrm{rad}}$ " is the rate of heat transfer by radiation, " $\in$ " is the emissivity of the plate surface, " $\odot$ " is the Stefan-Boltzmann constant, " $\mathrm{T}_{\text {surf }}$ " is the plate surface temperature, and " $\mathrm{T}_{\text {surr }}$ " is the temperature of the surroundings, which is often essentially the same as that of the surrounding air. The two temperatures in this equation must be in absolute temperature units, degrees Kelvin or degrees Rankine.

The experimental results for the three sample runs are as follows:

(a) Vertical Plate

Power input $=102.1$ watt

Plate temperature $=177 \mathrm{~F}$

Air temperature $=68 \mathrm{~F}$

Plate emissivity $=0.16$ (measured by a thermopile)

Calculated non-convective heat transfer $=25.2$ watt

Net convective heat transfer $=102.1-25.2=76.9$ watt

Textbook calculated convective heat transfer $=79.8$ watt

"Proceedings of the 2003 American Society for Engineering Education Annual Conference \& Exposition Copyright (C) 2003, American Society for Engineering Education" 
Percent difference between experimental and textbook convection $=3.8 \%$

\section{(b) Horizontal Plate with Exposed Surface Facing Upward}

Power input $=70$ watt

Surface temperature (exposed) $=165 \mathrm{~F}$

Surface temperature (insulated) $=224 \mathrm{~F}$

Air temperature $=68 \mathrm{~F}$

Plate emissivity $=0.16$

Calculated non-convective heat transfer $=19.4$ watt

Net convective heat transfer $=70-19.4=50.6$ watt

Textbook calculated convective heat transfer $=46.7$ watt

Percent difference between experimental and textbook convection $=7.7 \%$

\section{(c) Horizontal Plate with Exposed Surface Facing Downward}

Power input $=70$ watt

Surface temperature (exposed) $=202 \mathrm{~F}$

Surface temperature (insulated) $=242 \mathrm{~F}$

Air temperature $=64 \mathrm{~F}$

Plate emissivity $=0.16$

Calculated non-convective heat transfer $=28.8$ watt

Net convective heat transfer $=70-28.8=41.2$ watt

Textbook calculated convective heat transfer $=36.0$ watt

Percent difference between experimental and textbook convection $=12.6 \%$

In summary, the difference between the experimental and textbook values for the natural convection heat transfer ranged between 3.8 and $12.6 \%$ for these three sample runs.

\section{Conclusions}

Use of the demonstration unit in lecture class provides many benefits. With the students operating the equipment and performing calculations during the class period, a more visual and interactive environment is created. Through immediate comparison of the experimental results with the theoretical predictions, the students gain a better appreciation of the applicability and limitations of the theoretical equations for determination of convective heat transfer coefficients.

Use of the unit also emphasizes the fact that radiative heat transfer often accompanies convective heat transfer. Therefore, when investigating convective heat transfer, adjustments should usually be made to the experimental data to correct for the radiation contribution.

"Proceedings of the 2003 American Society for Engineering Education Annual Conference \& Exposition Copyright (C) 2003, American Society for Engineering Education" 
The demonstration unit has been well-received by the students, who find it to be a welcome visual supplement to the lecture presentation on empirical relations for convection. It encourages student participation and results in more interaction between the students and the instructor. In addition to its use in lecture classes, the unit has been incorporated as a permanent experiment in the senior level heat transfer laboratory.

In conclusion, it is believed that use of the demonstration unit in lecture classes significantly enhances the educational experience of the students and improves the students' comprehension of the lecture material.

\section{CHARLES H. FORSBERG}

Charles H. Forsberg is an Associate Professor of Engineering at Hofstra University, where he teaches courses in the thermal/fluids area. He received a B. S. in Mechanical Engineering from the Polytechnic Institute of Brooklyn (now Polytechnic University), and an M. S. in Mechanical Engineering and Ph. D. from Columbia University. He is a Licensed Professional Engineer in New York State.

"Proceedings of the 2003 American Society for Engineering Education Annual Conference \& Exposition Copyright (C) 2003, American Society for Engineering Education” 